\title{
First Record of Trophobiotic Interaction between a Ponerine Ant and a Cicadelid Bug
}

\author{
Thadeu Sobral Souza $^{1}$ and Ronaldo B. Francini ${ }^{2}$ \\ ${ }^{1}$ Programa de Pós Graduação em Ecologia, Instituto de Biologia, Universidade Estadual de Campinas, 13083-970 Campinas, SP, Brazil \\ ${ }^{2}$ Curso de Ciências Biológicas, Universidade Católica de Santos, Campus D. Idílio José Soares, 11015-200 Santos, SP, Brazil
}

Correspondence should be addressed to Ronaldo B. Francini, francini@unisantos.br

Received 16 March 2010; Accepted 28 April 2010

Academic Editor: Martin H. Villet

Copyright (C) 2010 T. S. Souza and R. B. Francini. This is an open access article distributed under the Creative Commons Attribution License, which permits unrestricted use, distribution, and reproduction in any medium, provided the original work is properly cited.

\begin{abstract}
The interactions of the ant Odontomachus bauri with nymphs of the sap-sucking bug Xedreota tuberculata (Cicadellidae: Ledrinae) were studied on Sipanea aff. (Rubiaceae) along a trail in an upland forest in the Ecological Reserve of Anavilhanas, AM, Brazil. Five complete interactions at day and at night (about 60 minutes) were analyzed. The care of cicadelid nymphs ranged between 12 and 961 seconds.
\end{abstract}

\section{Introduction}

Ants are the main arthropod predators in tropical forests [13] with many species using plants as shelters or foraging areas [4-7]. Some of these interactions are obligatory and several other facultative with plants attracting ants opportunistically. Extrafloral nectaries (EFNs) which are present in at least 66 angiosperm families $[8,9]$ or food bodies, present in at least 20 angiosperm families, are the main attractive agent and consequently, promote myrmecophily [10]. The presence of some insects such as bugs (Insecta: Hemiptera) on a plant is virtually a guaranty of the presence of ants which attend them $[5,11-13]$. These insects suck the phloem and secret honeydew from the anus which is fed on by some ant species [14-17].

Recent revisions on Hemiptera-Formicidae interactions include [18-20]. Ponerine ants are mainly solitary predators $[1,11]$, and some of them live in plants with EFNs or bearing sap-sucking bugs $[1,21]$.

Sap-sucking bugs generally secret honeydew by ejecting high pressure drops some distance from insect body. This action avoids the attraction of predators and the development of mold in the colony and reduces the chance of colony drowning. Ants inhibit this behavior [22] eliciting the bug body with their antennas to obtain a perfect extruded drop which they then collect $[23,24]$.
Historically trophobiotic interactions between ponerine ants and cicadelid bugs have been little known [25]; the goal of this work was to describe our observations made in the Amazon on the interaction between workers of the ant Odontomachus bauri (Hymenoptera: Formicidae, Ponerinae) and nymphs of Xedreota tuberculata (Hemiptera: Cicadellidae).

\section{Materials and Methods}

The ant was identified following $[26,27]$ and the hemiptera following [28-30] and confirmed by Dr. Chris Dietrich (Center for Biodiversity, Illinois Natural History Survey) with vouchers deposited in the collections of MZUSP (USP) and MHNU (UNICAMP).

The observations were made on two plants of Sipanea aff (Rubiaceae; Figure 2(a)), the first with 35 leaves, a height of $110 \mathrm{~cm}$, and distant $140 \mathrm{~cm}$ away from the second with 15 leaves and a height of $60 \mathrm{~cm}$, which were located in a trail behind Base de Pesquisas Dois on the Ecological Reserve of Anavilhanas, Brazil ( $2^{\circ} 32^{\prime} 01^{\prime \prime} \mathrm{S} ; 60^{\circ} 50^{\prime} 03^{\prime \prime} \mathrm{W}$ ). The higher plant grew next to a decomposing trunk which was diagonally placed in the trail with the nest of Odontomachus bauri being located at the base of this plant. 


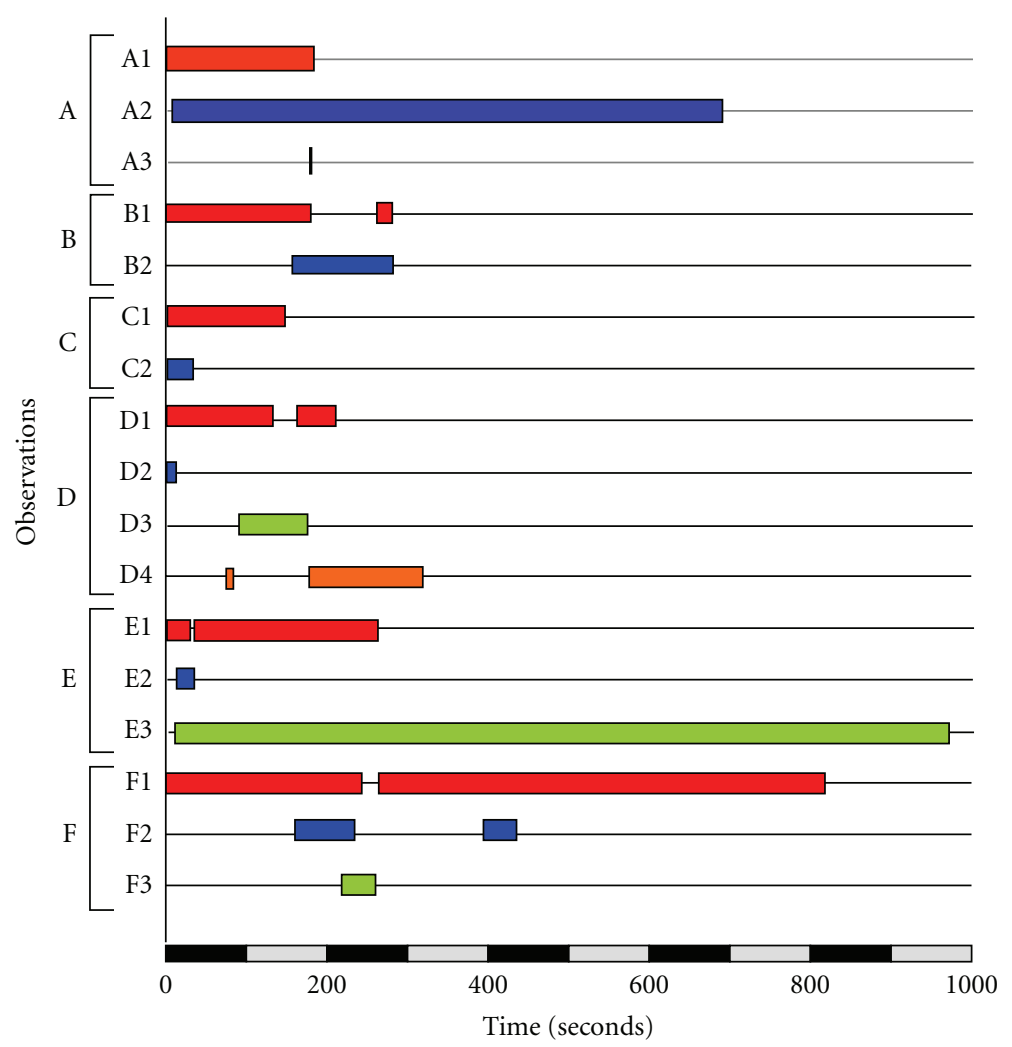

Figure 1: Duration of six video sessions of the interaction between different individuals of Odontomachus bauri attending nymphs of Xedreota tuberculata. The different colors represent different individuals of Odontomachus bauri observed simultaneously.

From July 13th to July 19th, we observed the interactions between the cicadelid nymphs and ants during the day and night. A total of 240 minutes of ant-cicadelid interaction were recorded on video, comprising six sequences of approximately 60 minutes each. We considered a sequence as the moment of arrival of an ant at the nymph location, its interactions with the nymphs, and the departure of ant from the group of nymphs.

\section{Results and Discussion}

This was the first time that $X$. tuberculata was found on Sipanea aff. (Rubiaceae) although [31] reported this species as a generalist, found on plants of the families Lauraceae, Leguminosae, Caesalpiniaceae, and Bombacaceae.

The workers of $O$. bauri attended the nymphs of $X$. tuberculata both during the day (morning and afternoon) and at night. The nymphs of $X$. tuberculata focussed on feeding on the more apical stems of the plant, where the stem or leaves are red. The care of nymphs ranged between 12 and 961 seconds not fitting a normal distribution (mean = 196.2 seconds; variance $=74674.32$ seconds; kurtosis $=3.20$; skewness $=1.97)($ Figure 1A-F). Between 2 and 4 ants were observed interacting with a group of nymphs (Figure 1D). During the longest video sequence, one ant spent 961 seconds in the presence of two other ants (Figure 1E). When eliciting a nymph the ants vibrated their antennas on the anterior region of the bug's abdomen (Figure 2(a)). The ant would consume the drop either directly from bug's anus with open jaws (Figure 2(b)) or by capillary action in the space between the closed or partially closed jaws. When full replenished the ant would return to the nest. Occasionally, ants were observed patrolling the plants where the nymphs were located occasionally stopping to check for nymphs.

If the plant was disturbed, the ants would respond, descending to the base. An attempt to remove one stipule caused an ant to bite the tweezers used. Two species of ant (Crematogaster sp and an unidentified formicine) were observed in close proximity to the Odontomachus ant, without eliciting a response.

According to [11], Odontomachus species are solitary forest predators; however this research has shown that $O$. bauri showed a nonpredatory behavior known towards $X$. tuberculata, a cicadelid bug capable of producing honeydew. This behavior has also been observed among some Ponerinae species which are used to collect the honeydew produced by hemipterans including: $O$. haematodus, from west Africa [32], and the American species O. troglodytes [33] from Cuba, Ectatomma tuberculatum (Colombia) and E. ruidum [34] from Ecuador and Trinidad, and E. sp. [35] from Guyana. In addition, L. Passos and P. S. Oliveira [36] found Odontomachus chelifer as disperser of nonmyrmecophilous seeds present in the soil of tropical forests in the coastal areas 


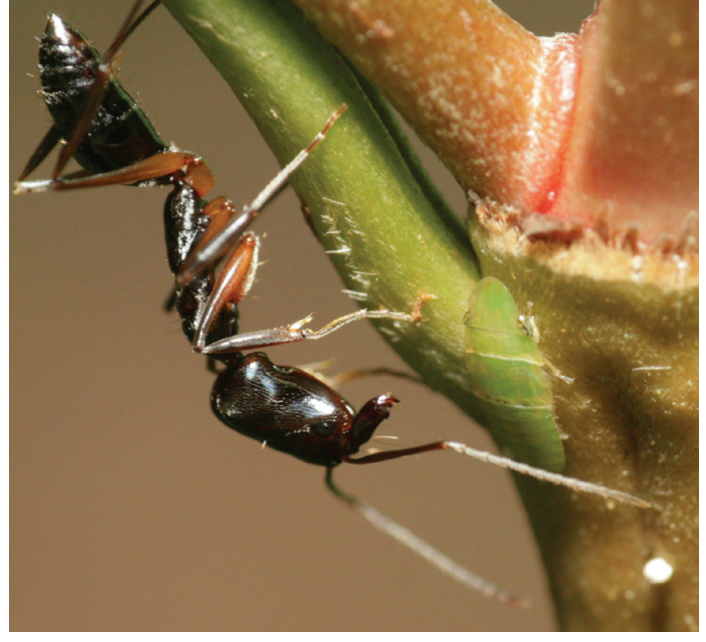

(a)

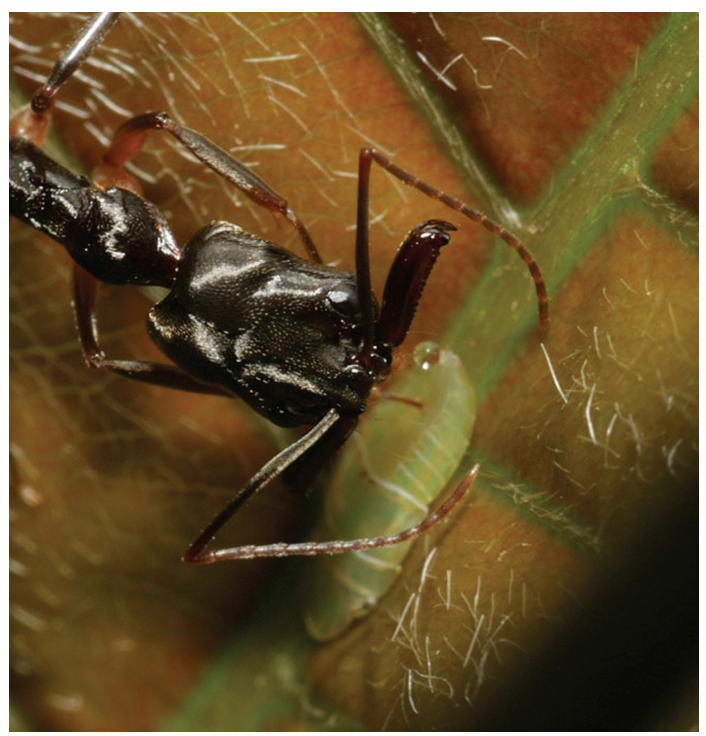

(b)

Figure 2: $(\mathrm{a}, \mathrm{b})$ interaction of a worker of Odontomachus bauri to obtain a drop of the sugar liquid secreted by the nymph.

of southeastern Brazil. Thus it would seem that ants of the genus Odontomachus are not strictly predators and are able to feed off both honeydew and seeds.

\section{Acknowledgments}

The authors would like to thank MsC Daniel de Paiva Silva (UNICAMP), Dr. Kleber Del-Claro (UFU), and Dr. Woodruff Whitman Benson (UNICAMP) for the detailed revision of the paper and Dr. Chris Dietrich (Center for Biodiversity, Illinois Natural History Survey) for the identification of the cicadelid bug. They also are grateful to IBAMA, for the authorization to perform this study in the Reserva Ecológica de Anavilhanas and Ms. Bruno Marchena Tardio for the help in the field.

\section{References}

[1] B. Holldobler and E. O. Wilson, The Ants, The Belknap, Cambridge, UK, 1990.

[2] V. Novotny, Y. Basset, J. Auga, et al., "Predation risk for herbivorous insects on tropical vegetation: a search for enemyfree space and time," Australian Journal of Ecology, vol. 24, no. 5, pp. 477-483, 1999.

[3] A. Floren, A. Biun, and K. E. Linsenmair, "Arboreal ants as key predators in tropical lowland rainforest trees," Oecologia, vol. 131, no. 1, pp. 137-144, 2002.

[4] J. L. Bronstein, "The contribution of ant-plant protection studies to our understanding of mutualism," Biotropica, vol. 30, no. 2, pp. 150-161, 1998.

[5] R. C. Buckley, "Interactions involving plants, homoptera, and ants," Annual Review of Ecology and Systematics, vol. 18, pp. 111-135, 1987.

[6] D. W. Davidson and D. Mckey, "The evolutionary ecology of symbiotic ant-plant relationships," Journal of Hymenoptera Research, vol. 2, no. 1, pp. 13-83, 1993.

[7] C. R. Huxley and D. F. Cutler, Ant-Plant Interactions, Oxford University Press, Oxford, UK, 1991.

[8] B. L. Bentley, "Extrafloral nectaries and protection by pugnacious bodygards," Annual Review of Ecology and Systematics, vol. 8, pp. 407-427, 1977.

[9] V. Rico-Gray and P. S. Oliveira, The Ecology and Evolution of Ant-Plant Interactions, University Chicago Press, Chicago, Ill, USA, 2007.

[10] D. J. O'Dowd, "Pearl bodies as ant food: an ecological role for some leaf emergences of tropical plants ( mutualisms)," Biotropica, vol. 14, no. 1, pp. 40-49, 1982.

[11] C. R. Carroll and D. H. Janzen, "Ecology of foraging by ants," Annual Review of Ecology and Systematics, vol. 4, pp. 231-257, 1973.

[12] P. J. Gullan, "Relationships with ants," in Soft Scale InsectsTheir Biology, Natural Enemies and Control, Y. Ben-Dov and C. J. Hodgson, Eds., pp. 351-377, Elsevier Science, Amsterdam, The Netherlands, 1997.

[13] P. J. Gullan and M. Kosztarab, "Adaptations in scale insects," Annual Review of Entomology, vol. 42, pp. 23-50, 1997.

[14] J. H. C. Delabie, "Trophobiosis between formicidae and hemiptera (sternorrhyncha and auchenorrhyncha): an overview," Neotropical Entomology, vol. 30, no. 4, pp. 501-516, 2001.

[15] K. Del-Claro and P. S. Oliveira, "Ant-homoptera interactions in a neotropical savanna: the honeydew-producing treehopper, Guayaquila xiphias (Membracidae), and its associated ant fauna on Didymopanax vinosum (Araliaceae)," Biotropica, vol. 31, no. 1, pp. 135-144, 1999.

[16] K. Del-Claro and P. S. Oliveira, "Conditional outcomes in a neotropical treehopper-ant association: temporal and species-specific variation in ant protection and homopteran fecundity," Oecologia, vol. 124, no. 2, pp. 156-165, 2000.

[17] N. Blüthgen, M. Verhaagh, W. Goitía, K. Jaffé, W. Morawetz, and W. Barthlott, "How plants shape the ant community in the Amazonian rainforest canopy: the key role of extrafloral nectaries and homopteran honeydew," Oecologia, vol. 125, no. 2, pp. 229-240, 2000.

[18] J. H. C. Delabie and F. Fernandez, "Relaciones entre hormigas y homopteros (Hemiptera: Sternorrhyncha y Auchenorrhyncha)," in Introduccion a las Hormigas de la Region Neotropical, F. Fernandez, Ed., pp. 181-197, Instituto de Investigacion de Recursos Biologicos Alexander von Humboldt, Bogota, Colombia, 2003. 
[19] D. W. Davidson, S. C. Cook, and R. R. Snelling, "Liquidfeeding performances of ants (Formicidae): ecological and evolutionary implications," Oecologia, vol. 139, no. 2, pp. 255266, 2004.

[20] K. Del-Claro, "Multitrophic relationships, conditional mutualisms, and the study of interaction biodiversity in tropical savannas," Neotropical Entomology, vol. 33, no. 6, pp. 665-672, 2004.

[21] N. A. Weber, "The Neotropical coccid-tending ants of the genus Acropyga Roger," Annals of the Entomological Society of America, vol. 37, pp. 89-122, 1944.

[22] M. J. Way, "Mutualism between ants and honeydew producing Homoptera," Annual Review of Entomology, vol. 8, pp. 307344, 1963.

[23] W. M. Wheeler, Ants. Their Structure, Development and Behavior, Columbia University Press, New York, NY, USA, 1926.

[24] T. E. Mittler, "Studies on the feeding and nutrition of Tuberolachttus saligttus (Gmelin) 11. The nitrogen and sugar composition of ingested phloem and excreted honeydew," Journal of Experimental Biology, vol. 35, pp. 74-84, 1958.

[25] K. Del-Claro, personal communication.

[26] W. L. Brown, "Contributions toward a reclassification of the Formicidae. Part VI. Ponerinae, Tribe Ponerini, Subtribe Odontomachiti. Section A. Introduction, subtribal Characters, genus Odontomachu," Studia Entomologica, vol. 19, no. 1-4, pp. 67-171, 1976.

[27] J. T. Longino, "Ants of Costa Rica," 2008, http://www.evergreen.edu/.

[28] J. P. Kramer, "A revision of the new world leafhoppers of the subfamily Ledrinae (Homoptera: Cicadellidae)," Transactions of the American Entomological Society, vol. 92, no. 3, pp. 469502, 1966.

[29] C. H. Dietrich, "Keys to the families of Cicadomorpha and subfamilies and tribes of Cicadellidae (Hemiptera: Auchenorrhyncha)," Florida Entomologist, vol. 88, no. 4, pp. 502-517, 2005.

[30] J. R. Jones and L. L. Deitz, "Phylogeny and systematics of the leafhopper subfamily Ledrinae (Hemiptera: Cicadellidae)," Zootaxa, no. 2186, pp. 1-120, 2009.

[31] Y. Basset, N. D. Springate, and C. Elroy, "Folivorous insects in the rainforests of the guianas," in Tropical Forests of the Guiana Shield, D. S. Hammond, Ed., pp. 295-320, CAB International, 2005.

[32] H. C. Evans and D. Leston, "A Ponerine ant (Hym., Formicidae) associated with Homoptera on cocoa in Ghana," Bulletin of Entomological Research, vol. 61, pp. 357-362, 1971.

[33] J. G. Myers, "Observations on the biology of two remarkable cixiid plant-hoppers (Homoptera) from Cuba," Psyche, vol. 34, no. 4, pp. 283-292, 1929.

[34] N. A. Weber, "Two common ponerine ants of possible economic significance, Ectatomma tuberculatum (Olivier) and E. ruidum Roger," Proceedings of the Entomological Society of Washington, vol. 48, pp. 1-16, 1946.

[35] C. H. Dietrich and S. H. Mckamey, "Three new idiocerine leafhopper (Homoptera: Cicadellidae) from Guyana with notes on ant-mutualism and subsociality," Proceedings of the Entomological Society of Washington, vol. 92, pp. 214-223, 1990.

[36] L. Passos and P. S. Oliveira, "Interactions between ants, fruits and seeds in a restinga forest in south-eastern Brazil," Journal of Tropical Ecology, vol. 19, no. 3, pp. 261-270, 2003. 

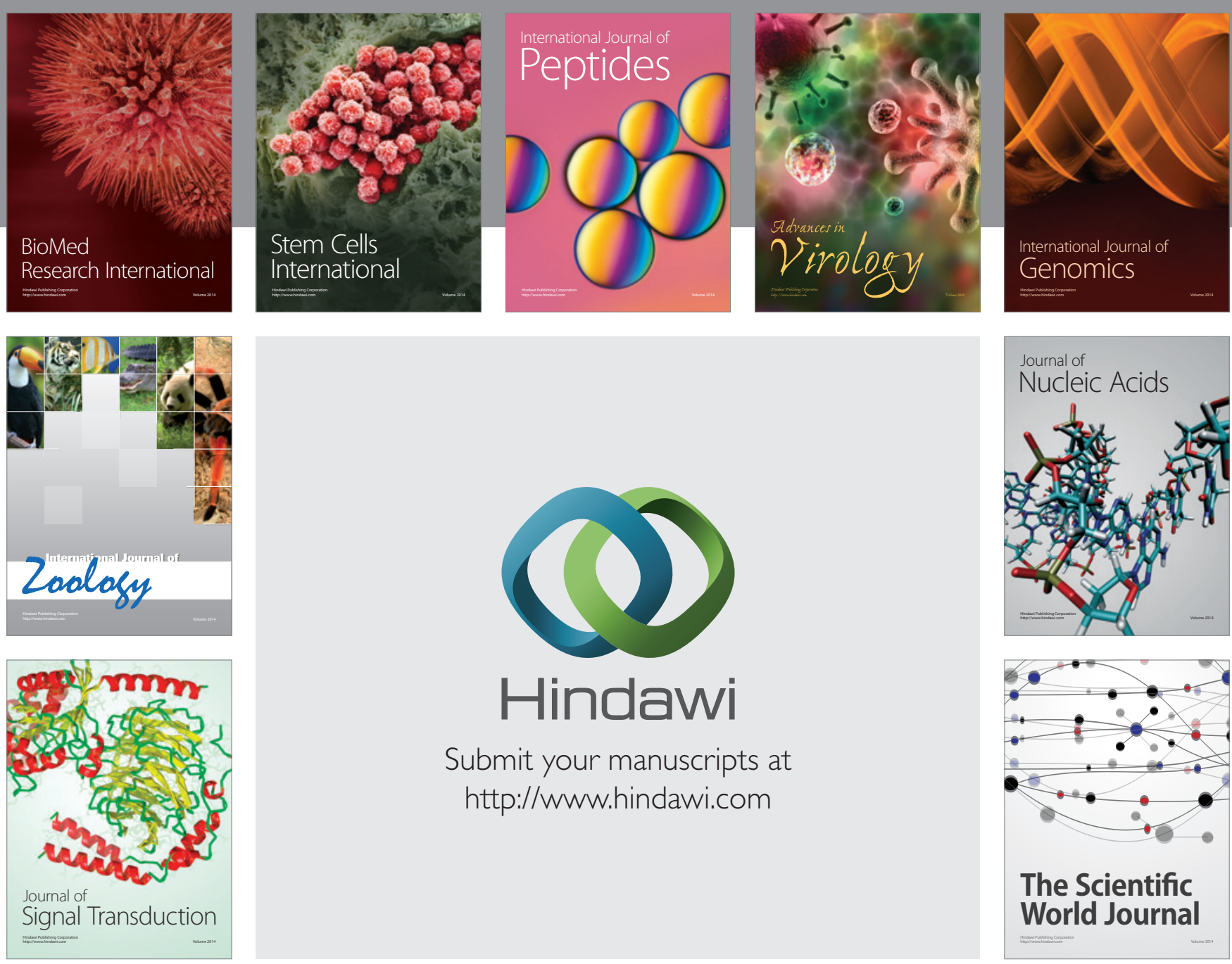

Submit your manuscripts at

http://www.hindawi.com
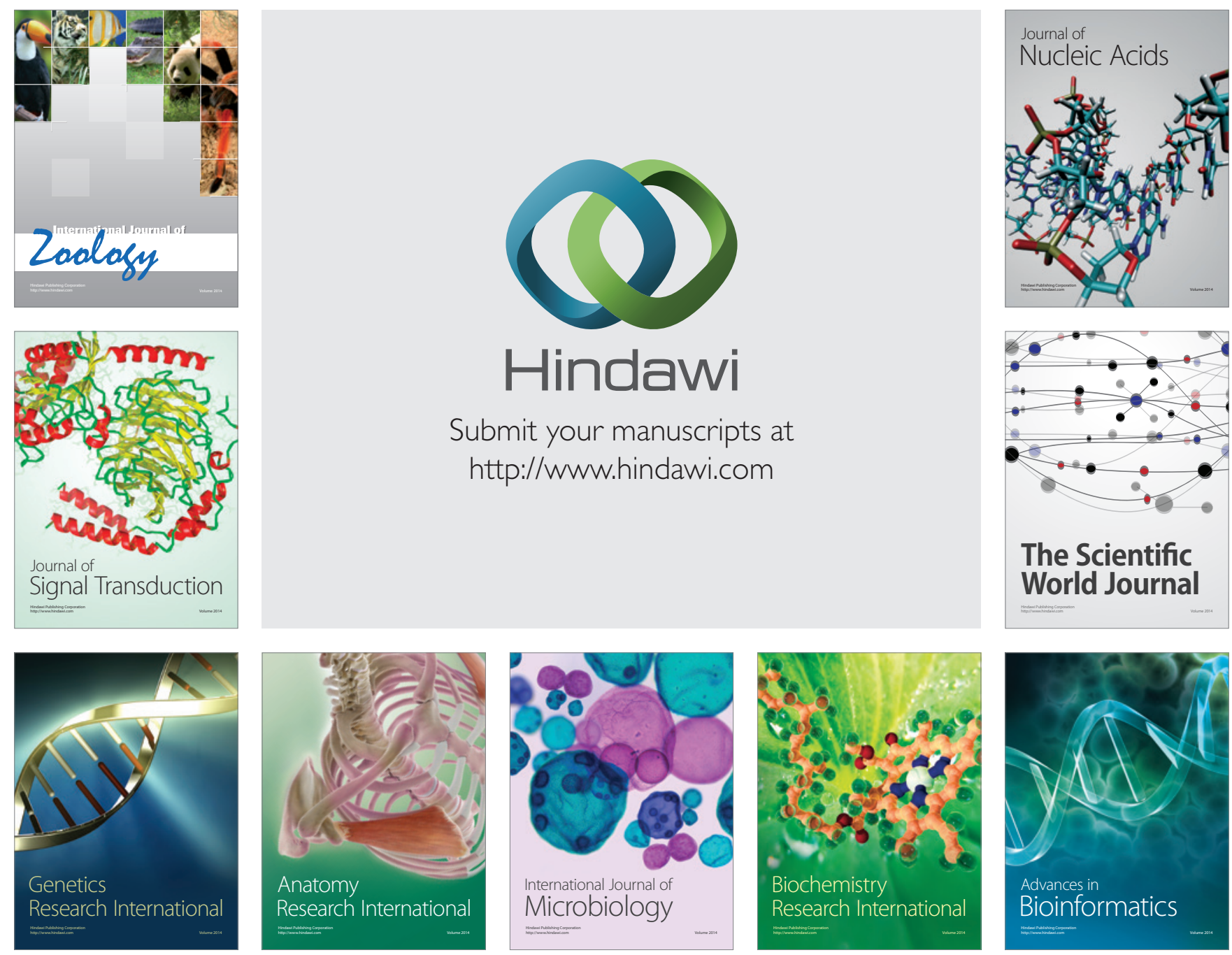

The Scientific World Journal
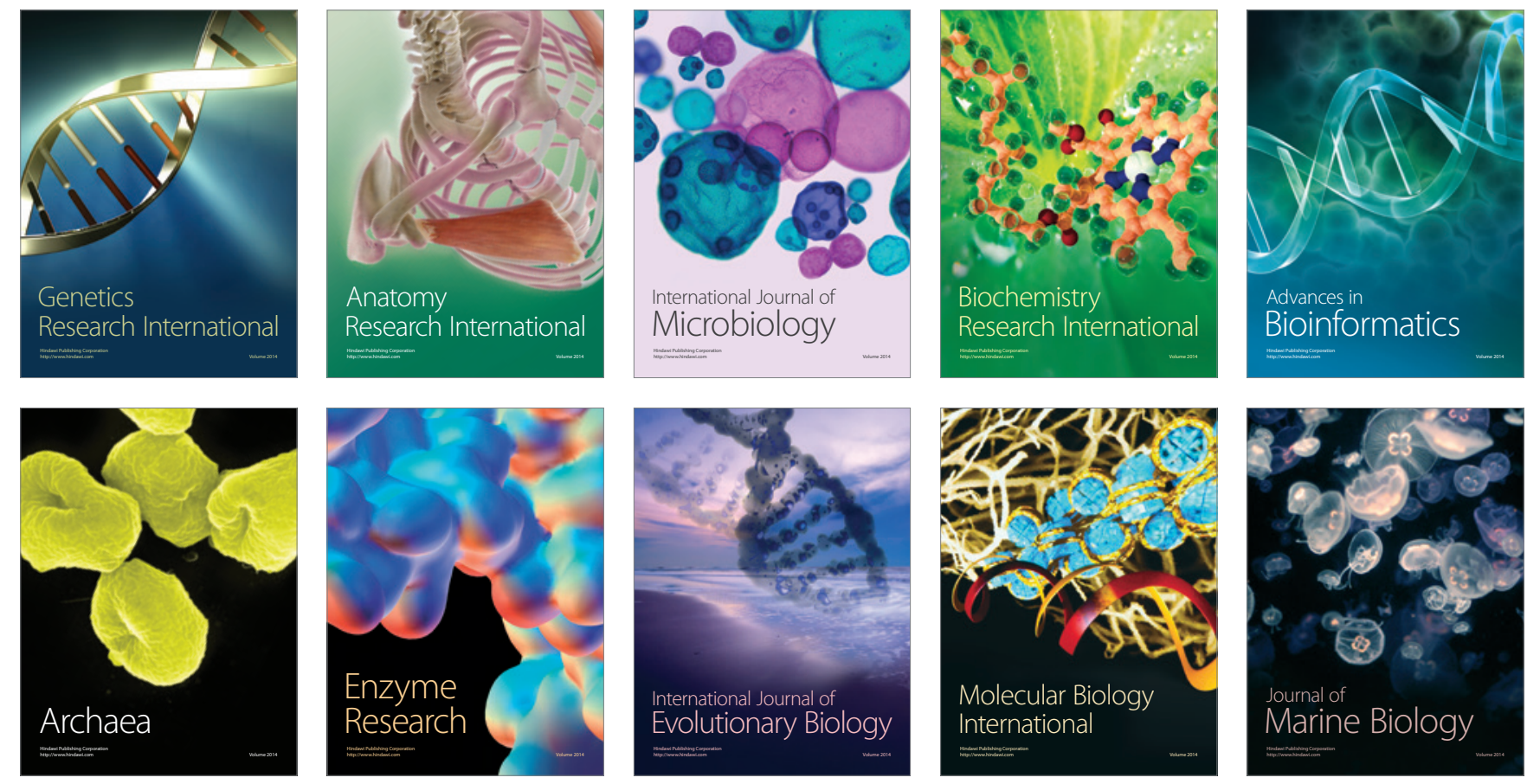